\title{
CONTEXTUALIZAÇÃO DO INSTITUTO FEDERAL DO TOCANTINS NA ESFERA DAS POLÍTICAS DE EDUCAÇÃO PROFISSIONAL E TECNOLÓGICA
}

http://dx.doi.org/10.5902/2176217115086

\author{
Ana Claudia Ferreira Rosa \\ Instituto Federal de Educação Ciência e Tecnologia do Tocantins, Brasil. \\ Janaína Miranda Muradás Amorim \\ Instituto Federal de Educação Ciência e Tecnologia do Tocantins, Brasil.
}

\author{
Lívia Fernanda Leal Macedo \\ Universidade Federal do Piauí, Brasil.
}

Resumo

O artigo apresenta o Instituto Federal de Educação, Ciência e Tecnologia do Tocantins no contexto da educação profissional e tecnológica no Brasil. O objetivo consiste em apresentar o Instituto Federal do Tocantins enfatizando a idiossincrasia de sua constituição com recorte para o atendimento assistencial aos alunos do campus Palmas. Utilizou-se da pesquisa bibliográfico-documental e a observação participante. A base teórica ampara-se nas seguintes leis: lei de criação dos institutos federais, no acordo de metas e compromissos para os fins de estruturação, organização e atuação dos institutos federais de educação e no decreto n. 7.234, de 19 de julho de 2010, do Programa Nacional de Assistência Estudantil, entre outros. Apresenta um breve panorama do Instituto Federal do Tocantins.

Palavras-chave: institutos federais, educação profissional e tecnológica, assistência estudantil.

\section{BACKGROUND OF THE OFFICE OF FEDERAL POLICY ON BALL TOCANTINS PROFESSIONAL EDUCATION AND TECHNOLOGY}

\footnotetext{
Abstract

The article presents the Federal Institute of Education, Science and Technology of Tocantins in vocational and technological education in Brazil. The objective is to present the Federal Institute of Tocantins emphasizing the idiosyncrasy of its constitution with cutout for assistance services to 
students on campus Palmas. We used the bibliographic and documentary research and participant observation. The theoretical basis bolsters on the following laws: law of the federal institutes of creation, in the target and commitment agreement for the purposes of structuring, organization and performance of the federal education and decree n. 7.234, of July 19, 2010, the National Student Assistance Program, among others. Provides a brief overview of the Federal Institute of Tocantins. Key-words: federal institutes, vocational and technological education, student assistance. 


\section{Introdução}

$\mathrm{O}$ $S$ institutos federais e neste contexto, o Instituto Federal de Educação Ciência e Tecnologia do Tocantins - IFTO - foi criado pela lei n. 11.892/2008, figurando no cenário nacional como política pública de ampliação de vagas no ensino superior, ao mesmo tempo em que resguarda o ensino médio integrado, com vagas de no mínimo $50 \%$ do quantitativo das vagas ofertadas. Esse viés caracteriza e especifica as atividades fins dos Institutos Federais, que apresentam a idiossincrasia de atendimento aos níveis da educação básica e superior, no mesmo espaço, aproveitando o corpo docente existente, de acordo com a lei em referência. O objetivo do estudo consiste, portanto, em apresentar o IFTO e sua constituição e atendimento aos dois níveis da educação: a educação básica e a educação superior com recorte para o atendimento assistencial aos alunos do campus Palmas.

Constitui o problema em questão: Como se contextualiza o Instituto Federal do Tocantins na esfera das políticas de educação profissional e tecnológica?

Utilizou-se como recurso metodológico a pesquisa bibliográfico-documental e a observação participante com delineamento de estudo de caso. Segundo Triviños (1987), "observar é destacar de um conjunto (objetos, pessoas, animais etc.) algo especificamente, prestando, por exemplo, atenção em suas características."

Quanto à abordagem do problema, o estudo assume a forma qualitativa, mas aspectos quantitativos foram analisados, pois se considera entre outros princípios, comuns a toda abordagem dialética, em consonância com Gil (2006, p. 31), "o princípio da transformação das mudanças quantitativas em qualitativas, segundo o qual, quantidade e qualidade são características imanentes (inerentes) a todos os objetos e fenômenos, e estão interrelacionados."

\section{O IFTO no contexto da criação dos institutos federais}

Desde 1909, iniciando o século 20, as políticas públicas voltadas para a formação de operários para 0 atendimento das fábricas viram na educação profissional, meios para suprirem essa demanda. Para a consecução da proposta, contudo preteriram outras formas de viabilização para instituição de ensino técnico criando por decreto quatro escolas profissionais. Esta iniciativa foi decisão do então presidente do Estado do Rio de Janeiro Nilo Peçanha. Este, a partir de 1909, ao assumir a presidência do Brasil estende o pioneirismo do ensino técnico como política de atendimento público e com o decreto 7.566/1909 criou 19 escolas de aprendizes artífices (Brasil, 2009b).

A configuração do ensino técnico e profissional como instrumento a serviço do progresso econômico, minimizando o valor da instrução em prol dos trabalhadores foi retratado no discurso de posse do presidente Afonso Pena, em 1906: "A criação e multiplicação dos institutos de ensino técnico e profissional muito podem contribuir também para o progresso das indústrias, proporcionando-lhes mestres e operários instruídos e hábeis" (Brasil, 2009b).

O progresso da indústria figura sobremaneira superior ao progresso do indivíduo que trabalha. Não há de forma explícita pretensão do administrador em minimizar o trabalhador, posto que este não figura como ser a quem se destina maiores valores seja para exaltar ou 
depreciar é como uma extensão da máquina. Logo o discurso exalta o que há de mais significativo: o progresso das indústrias.

No governo de Juscelino Kubitschek nascem as escolas técnicas federais, resultado da transformação das escolas industriais e técnicas, no ano de 1959. Em 1971, com o espaço democrático ausente, dado o contexto histórico, impõem-se a Lei de Diretrizes e Bases da Educação - n. 5.692/71 - tornando compulsório o ensino técnico profissional todo o antigo $2^{\circ}$ grau.

Consubstanciando o momento ainda recente de abertura política, a Lei de Diretrizes e Bases da Educação a LDB 9.394/96 inova o conceito de ensino técnico, impondo direito subjetivo à certificação da aprendizagem técnica obtida fora do espaço escolar.

No que tange às leis que se sucederam firmando o princípio do Estado Democrático de Direito, as políticas educacionais continuam a serem firmadas através de decretos. Dentre outros, destacam-se o Decreto 2.208/97 que regulamentava a educação profissional e criava o Programa de Expansão da Educação Profissional - Proep -, que fora revogado pelo Decreto 5.154/2004 que permite a integração do ensino técnico de nível médio ao ensino médio. Figura ainda, no cenário das políticas publicas voltadas para a educação profissional, o Decreto 5.840/06 que institui o Programa Nacional de Integração da Educação Profissional com a educação básica na modalidade da Educação de Jovens e Adultos - Proeja. No bojo da revogação do decreto n. 2.208/97, Frigotto, Ciavatta e Ramos afirmam que

no âmbito da elaboração das políticas para o ensino médio e para a educação profissional, a revogação do Decreto n. 2.208/97 tornou-se emblemática da disputa e a expressão pontual de uma luta teórica em termos da pertinência político-pedagógica do ensino médio integrado à educação profissional. (Frigotto; Ciavatta; Ramos, 2005)

Consoante à necessidade de o governo comprometer-se com os anseios e necessidades populares, que imprimiam, ao decreto revogado, o caráter de instrumento voltado ao interesse do mercado em detrimento da formação integral do ser humano. Em aquiescência com o argumento pela inclusão, reitera-se que se faz premente considerar a educação como um direito para todos os segmentos populacionais. Ao Estado cabe ressignificar as políticas públicas para a educação e, sobretudo assumir o ônus da exclusão promovendo sua eliminação. O Estado chama para si, em consonância com as necessidades econômicas vigentes, a promoção se não do ser social diretamente, mas da força motriz que conduzirá o país ao progresso proclamado na bandeira nacional.

Desde a Lei de Diretrizes e Bases da Educação, há o esforço de efetivar ações coordenadas para o atendimento da educação. Fato revelador da estrutura política em prol do social é o espaço para as ações afirmativas nunca dantes posto em discussão, com ampla participação.

Em 29 de dezembro de 2008 foi implantada a lei n. 11.892, que criou no Brasil 38 institutos federais de educação, ciência e tecnologia, formados pela união dos centros federais de educação tecnológica, escolas agrotécnicas e escolas técnicas vinculadas a universidades. Conforme o art. 2, da lei n. 11.892/2008, 
os institutos federais são instituições de educação superior, básica e profissional, pluricurriculares e multicampi, especializados na oferta de educação profissional e tecnológica nas diferentes modalidades de ensino, com base na conjugação de conhecimentos técnicos e tecnológicos com as suas práticas pedagógicas.

\section{O IFTO em números: tipos de cursos e quantitativo de estudantes}

Os Institutos Federais nascem das antigas Escolas de Aprendizes e Artífices por intermédio de Nilo Peçanha em 1909, pelo decreto n. 7.566, onde essas eram destinadas a "órfãos e desvalidos da sorte", mas não tinham um papel definido de que tipo de educação a ser ofertada, pois nem eram escolas, como também oficinas (Oliveira, 2003).

Percebe-se que, enquanto concepção, os institutos são voltados para o desenvolvimento regionalizado e local, conforme o Termo de Acordos de Metas e Compromissos assinado pelo Ministério da Educação - MEC - e o IFTO em junho de 2010 ressalta o compromisso do IFTO com a comunidade, a partir da "necessidade da diversificação da oferta de cursos, [...] sintonizados com as demandas que contribuam para o desenvolvimento local e regional". Discurso presente também na lei de criação dos institutos federais, n. 11.892/2008, art. 6º inciso IV, onde trata uma das finalidades e características: "orientar sua oferta formativa em benefício da consolidação e fortalecimento dos arranjos produtivos, sociais e culturais locais, identificados com base no mapeamento das potencialidades de desenvolvimento socioeconômico e cultural no âmbito de atuação do instituto federal."

Sobre a constituição do IFTO, trata-se de uma instituição fundada pela integração da Escola Técnica Federal de Palmas e de sua Unidade Descentralizada, localizada no município de Paraíso do Tocantins, como também pela Escola Agrotécnica Federal de Araguatins. Tem como natureza a concepção da própria Lei de criação, n. 11.892/2008.

No âmbito dos princípios e das finalidades, o Instituto é autônomo para criar cursos, quanto para extingui-los, desde que sejam na área de atuação territorial e os mesmos autorizados por uma instância maior na instituição, no caso um Conselho Superior. (Brasil, 2008).

O IFTO na esfera das ofertas educacionais tem a sua estrutura organizada através da formação inicial e continuada, voltadas para a Educação Profissional, seja técnica de nível médio (Proeja, Subsequente, Integrado), ou cursos de graduações (Licenciatura, Tecnologia e Bacharelado) e cursos de pós-graduações. Mas, trata-se de uma autonomia interligada com metas e compromissos, pois mesmo sendo uma instituição autônoma em criar e extinguir cursos deve garantir em cada exercício, o mínimo de $50 \%$ (cinquenta por cento) de suas vagas para educação profissional técnica de nível médio e $20 \%$ (vinte por cento) para cursos de licenciatura, programas de formação pedagógica para professores da Educação Básica (Brasil, 2008).

No quadro 1 apresentamos os cursos superiores ofertados no IFTO, no primeiro semestre do ano de 2013. 
Quadro 1 -

Cursos ofertados no IFTO em 2013.

\begin{tabular}{|c|c|c|c|}
\hline Tipo de curso & Curso & Modalidade & Campus \\
\hline Formação Inicial & Atendimento - Proeja - Integrado & Presencial & Palmas \\
\hline Formação Inicial & $\begin{array}{l}\text { Manutenção e Operação de } \\
\text { Microcomputadores - Proeja - Integrado }\end{array}$ & Presencial & Palmas \\
\hline Formação Inicial & $\begin{array}{l}\text { Operador de Computador - Proeja - } \\
\text { Integrado }\end{array}$ & Presencial & Araguaína \\
\hline Formação Inicial & Mulheres Mil & Presencial & $\begin{array}{l}\text { Araguatins } \\
\text { Gurupi } \\
\text { Porto Nacional }\end{array}$ \\
\hline Técnico & Técnico em Administração - Integrado & Presencial & Palmas \\
\hline Técnico & Técnico em Agrimensura - Integrado & Presencial & Palmas \\
\hline Técnico & Técnico em Agroindústria - Integrado & Presencial & $\begin{array}{l}\text { Paraíso do } \\
\text { Tocantins }\end{array}$ \\
\hline Técnico & Técnico em Agronegócio - Integrado & Presencial & $\begin{array}{l}\text { Gurupi } \\
\text { Palmas }\end{array}$ \\
\hline Técnico & Técnico em Agropecuária - Integrado & Presencial & Araguatins \\
\hline Técnico & Técnico em Eletrotécnica - Integrado & Presencial & Palmas \\
\hline Técnico & Técnico em Eventos - Integrado & Presencial & Palmas \\
\hline Técnico & Técnico em Informática - Integrado & Presencial & $\begin{array}{l}\text { Araguaína } \\
\text { Palmas } \\
\text { Paraíso do } \\
\text { Tocantins }\end{array}$ \\
\hline Técnico & Técnico em Mecatrônica - Integrado & Presencial & Palmas \\
\hline Técnico & Técnico em Meio Ambiente - Integrado & Presencial & $\begin{array}{l}\text { Paraíso do } \\
\text { Tocantins } \\
\text { Porto Nacional }\end{array}$ \\
\hline Técnico & $\begin{array}{l}\text { Técnico em Redes de Computadores - } \\
\text { Integrado }\end{array}$ & Presencial & Araguatins \\
\hline Técnico & Técnico em Comércio - Integrado - Proeja & Presencial & Gurupi \\
\hline Técnico & Técnico em Vendas - Integrado - Proeja & Presencial & Porto Nacional \\
\hline Técnico & Técnico em Agrimensura - Subsequente & Presencial & Palmas \\
\hline Técnico & Técnico em Agropecuária - Subsequente & Presencial & $\begin{array}{l}\text { Araguatins } \\
\text { Dianópolis }\end{array}$ \\
\hline Técnico & Técnico em Agronegócio - Subsequente & Presencial & Gurupi \\
\hline Técnico & $\begin{array}{l}\text { Técnico em Análises Clínicas - } \\
\text { Subsequente }\end{array}$ & Presencial & Araguaína \\
\hline Técnico & $\begin{array}{l}\text { Técnico em Controle Ambiental - } \\
\text { Subsequente }\end{array}$ & $\begin{array}{l}\text { Presencial } \\
\text { A distância }\end{array}$ & Palmas \\
\hline Técnico & Técnico em Edificações - Subsequente & Presencial & $\begin{array}{l}\text { Gurupi } \\
\text { Palmas }\end{array}$ \\
\hline Técnico & Técnico em Eletrotécnica - Subsequente & Presencial & Palmas \\
\hline Técnico & Técnico em Enfermagem - Subsequente & Presencial & Araguaína \\
\hline Técnico & Técnico em Informática - Subsequente & Presencial & $\begin{array}{l}\text { Dianópolis } \\
\text { Palmas } \\
\text { Paraíso do } \\
\text { Tocantins } \\
\text { Porto Nacional }\end{array}$ \\
\hline
\end{tabular}




\begin{tabular}{|c|c|c|c|}
\hline Técnico & $\begin{array}{l}\text { Técnico em Informática para Internet - } \\
\text { Subsequente }\end{array}$ & Presencial & Araguaína \\
\hline Técnico & Técnico em Hospedagem - Subsequente & Presencial & Palmas \\
\hline Técnico & Técnico em Logística - Subsequente & Presencial & Porto Nacional \\
\hline Técnico & $\begin{array}{l}\text { Técnico em Manutenção e Suporte em } \\
\text { Informática - Subsequente }\end{array}$ & A distância & Palmas \\
\hline Técnico & Técnico em Mecatrônica - Subsequente & Presencial & Palmas \\
\hline Técnico & Técnico em Meio Ambiente - Subsequente & A distância & $\begin{array}{l}\text { Paraíso do } \\
\text { Tocantins }\end{array}$ \\
\hline Técnico & Técnico em Secretariado - Subsequente & Presencial & Palmas \\
\hline Técnico & $\begin{array}{l}\text { Técnico em Segurança do Trabalho - } \\
\text { Subsequente }\end{array}$ & $\begin{array}{l}\text { Presencial } \\
\text { A distância }\end{array}$ & Palmas \\
\hline Técnico & $\begin{array}{l}\text { Técnico em Serviços Públicos - } \\
\text { Subsequente }\end{array}$ & A distância & $\begin{array}{l}\text { Paraíso do } \\
\text { Tocantins }\end{array}$ \\
\hline Licenciatura & Artes Cênicas & Presencial & Gurupi \\
\hline Licenciatura & Ciências Biológicas & Presencial & Araguatins \\
\hline Licenciatura & Ciências & Presencial & $\begin{array}{l}\text { Paraíso do } \\
\text { Tocantins }\end{array}$ \\
\hline Licenciatura & Computação & Presencial & $\begin{array}{l}\text { Araguatins } \\
\text { Porto Nacional }\end{array}$ \\
\hline Licenciatura & Física & Presencial & Palmas \\
\hline Licenciatura & Letras - Língua Portuguesa & Presencial & Palmas \\
\hline Licenciatura & Matemática & Presencial & $\begin{array}{l}\text { Palmas } \\
\text { Paraíso do } \\
\text { Tocantins }\end{array}$ \\
\hline Tecnologia & Alimentos & Presencial & $\begin{array}{l}\text { Paraíso do } \\
\text { Tocantins }\end{array}$ \\
\hline Tecnologia & Agronegócio & Presencial & Palmas \\
\hline Tecnologia & Gestão da Tecnologia da Informação & Presencial & $\begin{array}{l}\text { Paraíso do } \\
\text { Tocantins }\end{array}$ \\
\hline Tecnologia & Gestão Pública & Presencial & Palmas \\
\hline Tecnologia & Logística & Presencial & Porto Nacional \\
\hline Tecnologia & Sistemas Elétricos & Presencial & Palmas \\
\hline Tecnologia & Sistemas para Internet & Presencial & Palmas \\
\hline Bacharelado & Administração & Presencial & $\begin{array}{l}\text { Paraíso do } \\
\text { Tocantins }\end{array}$ \\
\hline Bacharelado & Agronomia & Presencial & Araguatins \\
\hline Bacharelado & Engenharia Civil & Presencial & Palmas \\
\hline
\end{tabular}

Fonte: Sistec/MEC - junho de 2013

As informações contidas no quadro 1 foram extraídas do Sistema Nacional de Informações da Educação Profissional e Tecnológica - Sistec - no mês de junho de 2013.

Sobre o quantitativo de estudantes do IFTO, pelo quadro 2 se mostra a distribuição de estudantes em curso, segundo o tipo de curso, modalidade, campus e quantitativo de estudante, no mês de junho de 2013. 
Quadro 2 -

Quantitativo de estudante no IFTO em 2013 por tipo de curso.

\begin{tabular}{|c|c|c|c|}
\hline Tipo de curso & Modalidade & Campus & N. de Estudantes \\
\hline \multirow{3}{*}{$\begin{array}{l}\text { Formação Inicial - Proeja - } \\
\text { Integrado }\end{array}$} & \multirow{3}{*}{ Presencial } & Araguaína & 40 \\
\hline & & Palmas & 349 \\
\hline & & Paraíso do Tocantins & 66 \\
\hline \multirow{4}{*}{ Formação Inicial - Mulheres Mil } & \multirow{4}{*}{ Presencial } & Araguatins & 60 \\
\hline & & Gurupi & 100 \\
\hline & & Palmas & 71 \\
\hline & & Porto Nacional & 45 \\
\hline Formação Continuada & Presencial & Paraíso do Tocantins & 27 \\
\hline \multirow{6}{*}{$\begin{array}{l}\text { Técnico - Integrado ao Ensino } \\
\text { Médio }\end{array}$} & \multirow{6}{*}{ Presencial } & Araguaína & 129 \\
\hline & & Araguatins & 623 \\
\hline & & Gurupi & 137 \\
\hline & & Palmas & 1.499 \\
\hline & & Paraíso do Tocantins & 351 \\
\hline & & Porto Nacional & 72 \\
\hline \multirow{4}{*}{ Técnico - Integrado ao Proeja } & \multirow{4}{*}{ Presencial } & Araguaína & 26 \\
\hline & & Araguatins & 43 \\
\hline & & Gurupi & 55 \\
\hline & & Porto Nacional & 39 \\
\hline Técnico - Concomitante & Presencial & Araguatins & 26 \\
\hline \multirow{7}{*}{ Técnico - Subsequente } & \multirow{7}{*}{ Presencial } & Araguaína & 668 \\
\hline & & Araguatins & 71 \\
\hline & & Dianópolis & 131 \\
\hline & & Gurupi & 192 \\
\hline & & Palmas & 1.892 \\
\hline & & Paraíso do Tocantins & 491 \\
\hline & & Porto Nacional & 154 \\
\hline Técnico - Subsequente & A distância & Palmas & 1.123 \\
\hline \multirow{5}{*}{ Licenciatura } & \multirow{5}{*}{ Presencial } & Araguatins & 345 \\
\hline & & Gurupi & 119 \\
\hline & & Palmas & 397 \\
\hline & & Paraíso do Tocantins & 159 \\
\hline & & Porto Nacional & 130 \\
\hline \multirow{3}{*}{ Tecnologia } & \multirow{3}{*}{ Presencial } & Palmas & 1.355 \\
\hline & & Paraíso do Tocantins & 110 \\
\hline & & Porto Nacional & 182 \\
\hline \multirow{3}{*}{ Bacharelado } & \multirow{3}{*}{ Presencial } & Araguatins & 153 \\
\hline & & Palmas & 120 \\
\hline & & Paraíso do Tocantins & 40 \\
\hline \multirow{2}{*}{ Pós-graduação - Lato sensu } & \multirow{2}{*}{ Presencial } & Palmas & 60 \\
\hline & & Paraíso do Tocantins & 25 \\
\hline Pós-graduação - Lato sensu & A distância & Porto Nacional & 60 \\
\hline \multicolumn{3}{|c|}{ udantes no If } & 11.735 \\
\hline
\end{tabular}

Fonte: Sistec/MEC, junho de 2013. 


\section{Assistência estudantil no IFTO - campus Palmas}

No campo educacional brasileiro atual há uma grande dicotomia entre as classes sociais que adentram nas instituições de ensino devido a várias demandas que dificultam o êxito e a permanência escolar como, por exemplo, questões sociais e econômicas.

A educação para se tornar direito de todos, assim como prevê a Constituição Federal de 1988, necessita se adequar às novas transformações societárias, focalizando, sobretudo as desigualdades sociais e econômicas que se permeiam entre os estudantes e dificultam a permanência na educação:

A educação passa a ser um direito público que deve ser dirigido a todas as classes sociais e a todos os níveis de idade, sem qualquer tipo de discriminação, devendo o Estado proporcionar condições para que todos tenham acesso de modo igualitário a esse direito. (Vasconcelos, 2010, p. 606)

As políticas públicas se entrelaçam para responder às necessidades que se desenvolvem na sociedade. Necessidades essas que se remetem às desigualdades sociais. Desta forma, a política educacional tenta contemplar as demandas sociais e econômicas no momento que se une a outras políticas e tenta elucidar questões sociais.

Assim, a política educacional percorre sua trajetória no cenário atual e busca uma redefinição no campo das políticas sociais, no momento em que busca elaborar programas e projetos que reivindiquem e concretizem melhorias nas condições de permanência dos estudantes e legitimação de direitos já existentes. Para isso, surgiu a política de assistência estudantil.

A partir do Plano Nacional de Educação, aprovado em 10 de janeiro de 2001, foi construído o Programa Nacional de Assistência Estudantil, decreto n. 7.234, de 19 de julho de 2010. Este decreto apoia a permanência de estudantes de baixa renda matriculados nas instituições federais de ensino superior. O objetivo é viabilizar a igualdade de oportunidades entre todos os estudantes e contribuir para a melhoria do desempenho acadêmico, a partir de medidas que buscam combater situações de repetência e evasão.

A assistência estudantil é uma política que perpassa várias outras políticas, pois a articulação é necessária para que possa propor aos usuários dos serviços melhoria das condições de renda, alimentação, transporte, moradia, entre outras. Além de proporcionar encaminhamentos e ações em conjunto com a área pedagógica e psicossocial.

A inserção dos estudantes, em situação de vulnerabilidade social e econômica, em programas de assistência estudantil pode contribuir na permanência e êxito deles nas instituições de educação no Brasil, tendo em vista as atividades escolares que demandam recursos financeiros, tais como: custeio de vale-transporte, alimentação, material didático, fotocópias, taxas de inscrições de cursos e participação em eventos escolares, moradia, entre outras.

O levantamento das dificuldades e necessidades dos estudantes por meio do diagnóstico do contexto social o qual estão inseridos torna-se primordial para a intervenção social e a articulação e execução de programas e projetos. 
Portanto, são necessárias ações que garantam e ampliem os direitos dos estudantes, contribuindo para uma educação pública de qualidade, que visem à preparação do exercício pleno da cidadania presente no processo ensino-aprendizagem.

No IFTO - campus Palmas - os serviços de assistência ao estudante iniciaram no ano de criação da instituição, em 2005. Uma equipe multidisciplinar de profissionais é voltada ao atendimento de estudantes, servidores e colaboradores terceirizados do IFTO, é composta por médicos, enfermeiros, auxiliar e técnico de enfermagem, dentistas, psicólogos, assistentes sociais e nutricionista. Além disso, o IFTO - campus Palmas proporciona o atendimento pedagógico por meio de equipe que integra pedagogos, técnicos em assuntos educacionais e supervisores educacionais.

A atuação multidisciplinar objetiva conjugar os diferentes tipos de saberes, formando uma rede de inter-relações, buscando a construção de técnicas e instrumentais que se estendem em possibilidades na perspectiva do acesso, desempenho e permanência de estudantes, na efetivação dos direitos, e formação de uma cultura pública democrática e que possam enfrentar os reflexos das questões sociais.

Tais reflexos se evidenciam a partir de situações observadas no cotidiano educacional como dificuldade de acesso às políticas públicas ou sociais e aos benefícios, número elevado de faltas injustificadas, evasão escolar, repetência, dificuldade de permanência e reprovação. Os aspectos destacados ocorrem em sua maior parte devido a questões econômicas, desemprego, renda per capita insuficiente para suprir necessidades básicas, problemas de saúde, uso de drogas, violência escolar e doméstica, dentre outros.

Nesse sentido, o IFTO - campus Palmas - buscou mediar e enfrentar as questões sociais a partir de instrumentais, estratégias e mecanismos, os quais buscam a apreensão das particularidades da realidade social do usuário e a viabilização de uma intervenção efetiva, no intuito de minimizar os impactos das expressões das questões sociais na vida dos estudantes.

Por meio do Regulamento do Programa de Assistência Estudantil, instituído em maio de 2011, foi implantada a política de assistência estudantil no âmbito do Instituto Federal do Tocantins. No referido ano criou-se um conjunto de ações voltadas ao atendimento de estudantes que se enquadram nos critérios estabelecidos, ou seja, os que possuem renda per capita familiar de até um salário mínimo e meio e que estejam regularmente matriculados em cursos oferecidos pelo IFTO - campus Palmas.

As ações da política de assistência estudantil visam à permanência e êxito na perspectiva de inclusão social, produção de conhecimento, melhoria de desempenho acadêmico e podem ser elencadas da seguinte forma: auxílio transporte; auxílio alimentação; auxílio moradia; auxílio material didático; auxílio uniforme; auxílio pais-estudantes (creche); auxílio emergencial; assistência médica, odontológica e psicossocial; arte, cultura, esporte e lazer e auxílio de formação profissional (estudante colaborador).

O processo de seleção do Programa de Assistência Estudantil é realizada por meio de edital e envolve várias etapas. É executado pela equipe de assistentes sociais e realizado durante o início do ano letivo. Quando há demanda e recurso financeiro disponível também no segundo semestre do ano letivo. 
A educação, para se tornar direito de todos, assim como prevê a Constituição Federal, necessita se adequar às novas transformações societárias, focalizando, sobretudo as desigualdades sociais e econômicas que permeiam entre os estudantes que possuem a necessidade de se autofinanciar. A LDB, aprovada em 20 de dezembro de 1996, contém dispositivos que amparam a assistência estudantil, entre os quais se destaca: "Art. 3으 $\mathrm{O}$ ensino deverá ser ministrado com base nos seguintes princípios: I - igualdade de condições para o acesso e permanência na escola". A LDB, no seu art. $1^{\circ}$, parágrafos $2^{\circ}$ e $3^{\circ}$, inciso XI, determina, ainda, que "a educação deve englobar os processos formativos e que o ensino será ministrado com base no princípio da vinculação entre a educação escolar, o trabalho e as práticas sociais" (Brasil, 1996).

O Plano Nacional de Educação, aprovado em 10 de janeiro de 2001, determina a adoção de programas de assistência estudantil tais como bolsa trabalho ou outros, destinados a apoiar os estudantes carentes que demonstrem bom desempenho acadêmico.

A partir do PNE foi construído o Programa Nacional de Assistência Estudantil, decreto $\mathrm{n}$. 7.234, de 19 de julho de 2010, o qual apoia a permanência de estudantes de baixa renda matriculados nas instituições federais de ensino superior. O objetivo é ampliar as condições de permanência dos jovens na educação superior pública federal por meio da democratização das condições de permanência, da minimização dos efeitos das desigualdades sociais e regionais, da redução das taxas de retenção e evasão e da contribuição para a promoção da inclusão social pela educação.

Os serviços de assistência ao estudante no IFTO campus Palmas iniciaram no ano de criação da instituição, ainda como Escola Técnica Federal em 2005. Atualmente, a Coordenação de Assistência ao Estudante e Servidor é composta por uma equipe multidisciplinar, voltada ao atendimento de estudantes, servidores e colaboradores terceirizados do IFTO, formada por médicos, enfermeiros, auxiliar e técnico de enfermagem, dentistas, psicólogo, assistentes sociais, fonoaudiólogo e nutricionista.

O Programa de Assistência Estudantil pelo IFTO - campus Palmas - é executado de acordo com critérios estabelecidos, tais como renda per capita familiar máxima exigida de até um salário mínimo e meio. De acordo com o edital 014/2013/IFTO do Programa de Assistência Estudantil do Campus de Palmas no ano de 2013 foram ofertadas: 350 bolsas de auxílio alimentação, para a concessão de isenção total da refeição diária no refeitório do campus Palmas, durante o semestre letivo; 150 bolsas de auxílio formação profissional, para a inserção do estudante em atividades no IFTO campus Palmas, visando à integração social, cultural e aperfeiçoamento profissional, de modo a proporcionar a complementação do processo de aprendizagem por meio do desenvolvimento de atividades orientadas; o valor do benefício é de até $50 \%$ do salário mínimo; 10 bolsas de auxílio creche: auxílio financeiro aos pais-estudantes com crianças entre quatro meses e seis anos de idade. $O$ valor do benefício corresponde a $30 \%$ do salário mínimo, pago por um período de quatro meses; - 10 bolsas de auxílios moradia: destina-se a despesas com aluguel de imóvel. O valor do benefício: até $30 \%$ correspondente ao salário mínimo, pago por um período de quatro meses; 15 bolsas de auxílio transporte rural e intermunicipal: auxílio para o pagamento de transporte aos alunos residentes em área rural ou em outros municípios que não disponham de transporte próprio ou fornecido 
pelos municípios de domicílio. O valor do benefício é de até $20 \%$ correspondente ao salário mínimo; 200 bolsas de auxílio transporte urbano: caracteriza-se no repasse mensal de auxílio financeiro ao valor gasto com o vale transporte estudantil durante os dias letivos, o valor corresponde a $10 \%$ do salário mínimo; auxílio emergencial: recurso financeiro concedido aos estudantes que não foram beneficiados com outros auxílios e que passam por situações emergenciais; o benefício será oferecido uma única vez ao ano. O benefício é de até $30 \%$ do salário mínimo vigente; bolsas de auxílio uniforme: consiste na concessão de duas camisetas padrão do IFTO ao estudante do campus Palmas. O benefício será destinado aos estudantes do Ensino Médio Integrado; 107 bolsas de auxílio material didático: oferta de material didático conforme a necessidade do estudante. $O$ auxílio visa reforçar a prática educativa em sala de aula com o fim de propiciar maior eficiência no processo ensino-aprendizagem, bem como contribuir para o comprometimento do estudante em sala de aula, auxiliando assim, no desenvolvimento de habilidades e construção de novos saberes. O benefício se constitui de repasse financeiro no valor de até $15 \%$ do salário mínimo vigente no início de cada semestre letivo.

O processo de acesso, permanência e conclusão qualifica-se como uma garantia do direito à educação. O direito à educação, sendo dever do poder público, é garantido à medida que são criados mecanismos concretos de efetivação desse direito. Os serviços assistenciais, a partir de ações e programas, destinados aos estudantes, podem contribuir para garantia de acesso e permanência.

\section{Conclusão}

Os dados referentes à criação dos institutos federais de educação e, particularmente, do IFTO, comprovam a ampliação de vagas na educação profissional. Quiçá esse crescimento seja refletido diretamente no desenvolvimento humano para além do progresso do sistema econômico vigente. Visando a atender a este preceito, o exercício profissional na área educacional tem como ponto focal o desenvolvimento e execução de programas e projetos que promovam o acesso, a permanência e o melhor aproveitamento escolar dos estudantes, buscando alternativas para os desafios impostos pela dinâmica da ordem do capital que interfere no acesso e qualidade da política educacional.

O IFTO, no contexto dos institutos federais, procura adequar-se as transformações societárias, abrangendo diferentes modalidades e níveis de ensino, alcançando diferentes segmentos ao tempo em que se constitui um desafio à gestão de suas atividades.

\section{Referências}

MEC. Acordo de Metas e Compromissos para os fins de estruturação, organização e atuação dos institutos federais de educação. Disponível em <http://www.ifto.edu.br/ifto cms/ docs/arquivos/060520131622ACORDODEMETAS.pdf>. Acesso em 8 ago., 2013.

BRASIL. Decreto n. 7.234, de 19 de julho de 2010. Dispõe sobre o Programa Nacional de Assistência Estudantil - Pnaes. Disponível em <http://www.planalto.gov.br/ccivil 03/ Ato2007-2010/2010/Decreto/D7234.htm>. Acesso em 9 out., 2012.

BRASIL. Constituição Federal. Constituição da República Federativa do Brasil. Brasília: 
Senado Federal, 1988.

BRASIL. Lei n. 11.892 de 28 de dezembro de 2008, sobre a criação dos Institutos Federais de Educação, Ciência e Tecnologia. Disponível em <http://www.planalto.gov.br/ccivil 03/ ato 2007-2010/2008/lei/l11892.htm>. Acesso em 10 ago., 2013.

BRASIL. Resolução CNE/CEB $n^{\circ} 3$ de 30 de setembro de 2009a, sobre a instituição do Sistema Nacional de Informações da Educação Profissional e Tecnológica (Sistec). Disponível em <http://portal.mec.gov.br/dmdocuments/rceb003 09.pdf. $>$. Acesso em 10 ago., 2013.

BRASIL. Decreto n. 7.234, de 19 de julho de 2010. Dispõe sobre o Programa Nacional de Assistência Estudantil - PNAES. Disponível em <http://www.planalto.gov.br/ccivil 03/ Ato2007-2010/2010/Decreto/D7234.htm>. Acesso em 12 out. 2012.

BRASIL. Lei n. 9.394, de 20 de dezembro de 1996. Estabelece as diretrizes e bases da educação nacional. LDB - Lei de diretrizes e bases da educação. Disponível em <http://www.planalto.gov.br/ccivil 03/leis/L9394.htm>. Acesso em 9 ago. 2013.

BRASIL. Lei n. 10.172, de 9 de janeiro de 2001. Aprova o Plano Nacional de Educação e dá outras providências. Disponível em <http://www.planalto.gov.br/ccivil 03/leis/leis 2001/l10172.htm>. Acesso em 9 jul. 2013.

BRASIL. Centenário da rede federal de educação profissional e tecnológica. Brasília: Ministério da Educação, 2009b.

BRASIL. Lei n. 5.692, de 11 de agosto de 1971. Fixa as diretrizes e bases para o ensino de $1^{\circ}$ e $2^{\circ}$ graus, e dá outras providências. Disponível em <http://www.planalto.gov.br/ CCIVIL/LEIS/L5692.html>. Acesso em 15 jun., 2009.

BRASIL. Subsídios para o debate sobre o serviço social na educação: Grupo de estudos sobre - serviço social na educação. Brasília: CFESS, 2011. Disponível em <www.cfess. org.br/arquivos/subsídios-servico-social-na-educação.pdf>. Acesso em 30 abr., 2012.

FRIGOTTO, Gaudêncio, CIAVATTA, Maria; RAMOS, Marise. A gênese do decreto n. 5.154/2004: um debate no contexto controverso da democracia restrita. In: FRIGOTTO, G.; CIAVATTA, M.; RAMOS, M. (org.). Ensino médio integrado: concepção e contradições. São Paulo: Cortez, 2005, p. 21-56.

GIL, Antônio Carlos. Métodos e técnicas de pesquisa social. São Paulo: Atlas, 2006.

GUIMARÃES-IOSIF, Ranilse. Educação, pobreza e desigualdade no Brasil: impedimentos para a cidadania global e emancipatória. Brasília: Liber Livro, 2009.

IFTO. Critérios de seleção do Setor de Serviço Social. Palmas: IFTO, 2011.

IFTO. Portaria n. 195 de 19 de agosto de 2009, que aprova o Estatuto do Instituto Federal de Educação, Ciência e Tecnologia do Tocantins (IFTO). Disponível em $<$ http://www.in.gov.br/imprensa/visualiza/index.jsp?jornal=1\&pagina=11\&data=20/08/2009>.

Acesso em 8 ago., 2013.

IFTO. Edital n. 14, de 23 de abril de 2013 - seleção de candidatos às vagas do programa de assistência estudantil. Palmas: IFTO, 2013.

IFTO. Regulamento do programa de assistência estudantil - IFTO. Palmas: IFTO, 2011.

MAURIEL, Ana Paula Ornellas. Capitalismo, políticas sociais e combate à pobreza. ljuí: Unijuí, 2010. 
OLIVEIRA, Maria Auxiliadora Monteiro. Políticas públicas para o ensino profissional: o processo de desmantelamento dos Cefets. Campinas: Papirus, 2003.

TRIVIÑOS, Augusto Nibaldo Silva. Introdução à pesquisa em ciências sociais. São Paulo: Atlas, 1987.

VASCONCELOS, Natália Batista. Programa Nacional de Assistência Estudantil: uma análise da evolução da assistência estudantil ao longo da história da educação superior no Brasil. Ensino Em-Revista, Uberlândia, v. 17, n. 2, 2010, p. 599-616.

Ana Claudia Ferreira Rosa é estudante do curso de mestrado em Educação do Programa de Pós Graduação em Educação da Universidade Federal de Santa Maria e professora no Instituto Federal de Educação, Ciência e Tecnologia do Tocantins. Endereço: Distrito Agroindustrial de Paraíso - Vila Santana - BR 153 - km 480 - 77600000 - Paraíso do Tocantins - TO - Brasil.

E-mail: anaclaudia@ifto.edu.br.

Janaína Miranda Muradás Amorim é pedagoga, estudante do curso de mestrado em Educação do Programa de Pós Graduação em Educação da Universidade Federal de Santa Maria e orientadora educacional no Instituto Federal de Educação, Ciência e Tecnologia do Tocantins.

Endereço: Avenida Joaquim Teotônio Segurado, Quadra 202 sul, ACSU-SE 20, Conj. 1, Lote 8 - 77020-450 - Palmas - TO - Brasil.

E-mail: janainamorim@ifto.edu.br.

Lívia Fernanda Leal Macedo é estudante do curso de mestrado em Educação do Programa de Pós Graduação em Educação da Universidade Federal de Santa Maria e assistente social na Universidade Federal do Piauí.

Endereço: Campus Universitário Ministro Petrônio Portella - Bairro Ininga - 77020-450

- Teresina -PI - Brasil.

E-mail: liviaflmacedo@hotmail.com.br.

Recebido em 8 de agosto de 2014.

Aceito em 14 de novembro de 2014. 